MILOŠ ĆIRIĆ

Evropski centar za mir i razvoj (ECPD UN) Menadžment u kulturi i umetnosti

DOI 10.5937/kultura1236355C

UDK 316.72(497.11)"200"

pregledni rad

\title{
KULTURNAANIMACIJAI INSTITUCIJEKULTURE
}

Sažetak: Kulturna tradicija Beograda, građena kroz nekoliko milenijuma uspona i padova, predstavlja jedan od najznačajnijih gradskih resursa. Međutim, kultura nije dobila zasluženo mesto u razvojnim planovima Srbije, pa samim tim ni Beograda. To stanje se mora što pre popraviti kroz niz sinhronizovanih i smislenih akcija, među kojima je $i$ oživljavanje ideje o kulturnoj animaciji, ne samo kao istraživačke teme već kao realne aktivnosti svih relevantnih institucija i ustanova kulture. Početne aktivnosti moraju da obuhvate utvrđivanje realnog stanja kulture u Beogradu kroz popis kulturnih ustanova svih nivoa i usmerenja, a takođe i kroz šire istraživanje kulturnih potreba i navika stanovnika Beograda. Na osnovu tih baznih pokazatelja treba definisati niz akcija za artikulisanje $i$ usmeravanje interesovanja stanovništva na pravu kulturu, ali oslobođenu elitističkih obeležja. Približavanje kulture širim slojevima stanovništva, kroz edukativne i inspirativne programe namenjene mlađoj populaciji, i organizovanje određenih programa u ruralnim i prigradskim područjima treba da budu ključni elementi novopokrenutih animativnih programa. Pored toga, već afirmisane ustanove kulture treba da se priključe ili da podrže aktivnosti kulturne animacije koje bi bile koordinirane na nivou gradske uprave.

Ključne reči: kulturna tradicija, ustanove kulture, kulturna animacija, gradska uprava

\section{Uvod}

Ovaj $\operatorname{rad}^{1}$ za osnovnu temu ima sociokulturnu animaciju, koja je nastala u praskozorju civilizacije verovatno kao spontani paralelni proces nastajanju kulture. Kako je po nekim antropološkim istraživanjima kultura nastajala kroz artikulisanje

1 Rad je baziran na istraživanju koje je sprovedeno u toku izrade magistarske teze autora sa naslovom „Kulturna animacija u institucijama kulture Beograda“" na ECPD UN, http://ecpd.org.rs/ 
primitivnih religioznih obreda, logično je zaključiti da su prvi animatori kulture bili izvođači tih religioznih obreda ili kako ih danas kolokvijalno nazivamo vračevi. Razvojem društvenih odnosa religija je dobijala svoje formalne oblike iz kojih su tokom istorije nastali kanoni sprovođenja verskih obreda, ali i ukupnog socijalnog ponašanja jedinki. $\mathrm{S}$ druge strane, paralelno sa tim procesima, ali veoma često i pod njihovim ogromnim uticajem, razvijali su se kultura i umetnost. $U$ toku celog perioda razvoja civilizacije sve do buržoaske revolucije, kulturna animacija je bila spontani proces vezan za aktivnosti prvenstveno umetnika, kao nosilaca razvoja kulture u užem smislu, i viših vladajućih slojeva društva, kao osnovnih konzumenata, i mecena kulturnoumetničkog stvaralaštva.

\section{Pojam i poreklo kulturne animacije}

Početkom devetnaestog veka dolazi do radikalnih promena $\mathrm{u}$ društvenim odnosima, koje su, u određenim vremenskim ciklusima, nastavile da se dešavaju sve do savremenog doba. Najznačajniji rezultat tih promena je industrijska revolucija, koja je kroz ogroman rast proizvodnje svekolikih dobara stvorila mogućnost za kreiranje potpuno novih, do tada u istoriji nepoznatih, društvenih odnosa. Sveopšta demokratizacija društvenih odnosa je dala ogroman zamah razvoju kulture i umetnosti kao jedne od najfascinantnijih tekovina civilizacije. Međutim novi društveni odnosi su doveli i do slobodnog nadmetanja, kako na tržištu roba i usluga tako i na polju ideja, stvaralaštva i estetskih vrednosti. U tim procesima su se formirali kulturni obrasci ponašanja određenih nacija, manje ili više usmeravani od strane vladajućih političkih opcija, koje su, shvatajući značaj kulture, počele da je koriste za sprovođenje svojih ciljeva. Ovo je važno razumeti kako bi se napravila razlika između kulturnog standarda i kulturnog nivoa, jer kako kaže Koković , „kulturni nivo je pokazatelj kultivisanosti, koji se ogleda u tome koliko su pojedinci, grupe ili društvo ovladali određenim vidovima delatnosti, obrascima ponašanja i kulturnim vrednostima prethodnih generacija. Kulturni nivo se manifestuje i definiše na različite načine. Nekada se izražavao kao broj biblioteka, filmskih dvorana, broja odštampanih knjiga i časopisa. Ali sve ovo ni izdaleka ne iscrpljuje obim pojma nivoa kulture koji se ne može identifikovati ni sa stepenom pismenosti ili obrazovanosti“.

Druga polovina dvadesetog veka će ostati zabeležena $u$ istoriji kao period rađanja nove postindustrijske civilizacije, koja će obeležiti ako ne ceo treći milenijum onda sigurno nekoliko prvih vekova trećeg milenijuma. Obilje slobodnog vremena, uz

2 Koković D., Pukotine kulture, Prometej, Novi Sad 2005, str. 27. 


\section{MILOŠ ĆIRIĆ}

udoban i brz masovni putnički transport, omogućili su da kultura postane dostupna svima, ali su istovremeno u ozbiljnim razmerama uzrokovali otuđenost pojedinaca i gubljenje koherencije nekadašnjih manjih socijalnih celina. Kako je ovaj proces počeo da poprima epidemijske razmere, naročito kod mlađe populacije, određene društvene strukture za brigu o omladini osmišljavaju koncept sociokulturne animacije ${ }^{3}$, koji je u savremenom značenju pokrenut $\mathrm{u}$ drugoj polovini prošlog veka od strane Francuskog omladinskog komiteta u cilju smanjivanja socijalnih tenzija i uspostavljanja balansa između individua i grupa $u$ velikim gradskim aglomeracijama. Duh sociokulturne animacije su označavale dve ključne reči, participacija i prilagođavanje promenama, na bazi kojih su, prema francuskom modelu, u nizu zemalja pokrenuti slični programi socijalne integracije. „U francuskom obliku animation socio-culturelle 4 poslije drugog svjetskog rata, kao i u engleskom obliku community development ${ }^{5}$, animacija je bila reakcija na neuspjeh kulturnih i obrazovnih djelatnosti (uključivši i socijalnu pomoć) prošlog stoljeća." ${ }^{\text {"6 En- }}$ ckevort dalje ističe da kulturna i sociokulturna animacija treba da podstaknu grupe iz određenih socijalnih slojeva, da postanu svesni sebe, kako bi se pospešila njihova opšta emancipacija. $\mathrm{Za}$ uspeh u tim nastojanjima presudnu ulogu imaju animatori različitih vrsta, Enckevort navodi desetak tipologija animatora, ali se oni ipak po sadržaju delanja mogu svrstati u dve osnovne komplementarne grupe. Prvu grupu čine kulturni animatori koji rade na širenju dostupnosti kulture i podsticanju pojedinaca da participiraju u kulturnom životu jer ,,puko izlaganje vrednostima kulture neće bez posredovanja drugog čovjeka uroditi kultiviranom ličnošću. To posredovanje nazivamo animacijom (animare, lat.=oživjeti, zadahnuti životom) ${ }^{\text {"c7 }}$, dok sociokulturni animatori, kao druga grupa animatora, nastoje da podstaknu socijalizaciju pojedinaca i poboljšaju odnosa u određenim socijalnim sredinama. Uvažavajući neosporan društveni značaj sociokulturne animacije, u ovom radu je ipak težište istraživanja usmereno na animaciju vezanu za kulturu i umetnost.

Razvoj animacije je, pored izraženih društvenih potreba, značajno podstaklo obilje ponude raznih kulturnih i zabavnih sadržaja,

3 Moulinier P., The Training of cultural animators, Cultural development: documentary dossier, vol. 18-19, UNESCO 1980, str. 14.

4 Sociokulturna animacija je prevod sa francuskog jezika sintagme Animation socio-culturelle.

5 Etimološko značenje ove sintagme je „razvoj zajednice“, ali suštinsko značenje je isto kao i Animation socio-culturelle.

6 Van Enckevort G., Status animatora, Kulturna i edukativna akcija u radnoj sredini i lokalnoj zajednici, priredili Kalanj R. i Sudović Z., Zagreb 1979, str. 194.

7 Dretar T., Animacija u kulturi, Kultura br. 45-46, Beograd 1979, str. 179. 


\section{MILOŠ ĆIRIĆ}

koji nisu usmereni samo ka lokalnom stanovništvu, čime se nametnuo novi pristup u promociji kulturno-umetničkih događaja kroz aktivnu kulturnu animaciju.

Koliko je ova tema važna govori niz projekata koje sprovodi Evropska Unija u okviru programa Evropske komisije Leonardo da Vinci - Transnational Networks. Jedan od takvih projekata je Animus ${ }^{8}$ na bazi koga su, u više zemalja EU, kreirane namenske radionice za animatore kulture u okviru visokoškolskih obrazovnih programa. Animatori se u tim radionicama za sociokulturnu animaciju osposobljavaju za rad sa ljudima i grupama radi usmeravanja i participiranja u životu zajednice u kojoj žive.

Polazeći od pretpostavke da sintagma ,sociokulturna animacija“ nije sasvim eksplicitna, radi potpunijeg razumevanja preuzeta je definicija animacije iz Izveštaja Evropske kulturne fondacije iz 1973. godine, koja daje njen veoma jasan psihološki i sociološki okvir kao značajne antropološke kategorije.

“Animacija je stimulacija za mentalni, fizički i emocionalni život ljudi u nekoj sredini kroz koju oni sebe pokreću da prihvate niz predstavljenih iskustva radi postizanja višeg stepena samopotvrđivanja, samodokazivanja, kao i višeg stepena svesti o pripadnosti zajednici na koju mogu da utiču.9"

Ova definicija implicira suštinu sociokulturne animacije, koja u svojoj osnovi ima tri bitne dimenzije: obrazovnu čiji je cilj lični razvoj; društvenu sa ciljem da se ojača grupa i zajednice i da se poveća učešće jedinki kao članova grupe ili zajednice; i kulturnu dimenziju koja ima za cilj razvijanje kreativnosti i raznovrsnosti izražavanja. ${ }^{10}$

Ali i pored značajnih napora koji se u poslednje vreme ulažu, kulturna animacija kao deo sociokulturne animacije ipak nije dovoljno istražena ni teoretski ni empirijski, o čemu govori činjenica da je objavljeno veoma malo radova sa tom temom. U nizu socioloških i antropoloških istraživanja, kulturna animacija se pominje u kontekstu razjašnjenja nekih činjenica vezanih za osnovne teme tih istraživanja, ali ne i kao poseban sociokulturni fenomen. Kako je suština animacije u praktičnim aktivnostima vezanim za socijalni i kulturni život, odnosno za podsticanje

8 An International Network for Training in Culture Animation, 2001 - 2004.

9 Simpson J. A., Sociocultural animation, in: Lifelong Education for Adults. An international handbook, eds. Titmus C. J., Pergamon Press, Oxford 1989, str. 54, citirano u Gilchrist R. i Jeffs T. - Settlements, Social Change and Community Action - Good Neighbours, London 2001, str.143, http://books. google.com/books

10 Citirano u: Foth M., Sociocultural animation, Queensland University of Technology, Australia 2006, http://eprints.qut.edu.au/1909/1/1909_1.pdf 
MILOŠ ĆIRIĆ

zainteresovanosti pojedinaca za umetnost, intelektualno stvaralaštvo i svoje životno okruženje, istraživanje koje je obavljeno u okviru elaboracije ove magistarske teze najvećim delom je usmereno na analiziranje aktivnosti koje sprovode reprezentativne institucije kulture i obrazovanja u Beogradu na promociji i afirmaciji kulture i umetnosti, a znatno manje na samu socioantropološku analizu fenomena kulturne animacije.

\section{Problem i teorijski kontekst problema}

Po svom sadržaju kulturna animacija predstavlja deo kulturne antropologije, kao naučne discipline koja proučava sve aspekte kulturne komunikacije u složenom odnosu kulture i društva. Ali njena struktura u velikoj meri obuhvata i određene sadržaje sociologije, psihologije $\mathrm{i}$ andragogije, što implicira veoma kompleksan kontekst teme ovog rada.

Polazeći od aktuelne gradske kulturne politike i sadržaja kulturnih događanja u Beogradu, teorijski kontekst problema se odnosi na utvrđivanje potreba za kulturnom animacijom uzimajući u obzir, kako kaže Cvetičanin, da ,ogroman deo populacije ne učestvuje ili ne želi da učestvuje u ovako koncipiranom javnom kulturnom životu, da su za veliki deo populacije postojeći kulturni programi nedostupni (konceptualno, finansijski i teritorijalno), iz čega proizilazi da postoji značajna potreba za dobrim poslovnim marketinškim pristupom i za osmišljenim programima sociokulturne animacije $e^{\text {"111. }}$.

O kulturnoj animaciji na našim prostorima se počelo govoriti još šezdesetih godina prošlog veka, kada se beleži otvaranje niza kulturnih centara sa potpuno drugačijim sadržajima i programskim šemama, u odnosu na domove kulture koji su se masovno otvarali posle drugog svetskog rata. Organizacija i delatnosti tih kulturnih centara su kreirani po uzoru na francuske kulturne centre, koje je kao oblik demokratizacije kulture gradio širom Francuske prvi posleratni ministar kulture u De Golovoj vladi Andre Malro (André Malraux ${ }^{12}$ ), smatrajući da građani imaju neotuđivo pravo na kulturu kao javno dobro, i odbacujući stav da je kultura privilegija elite. Ovakvi kulturni centri su imali brojne funkcije, ali su sve one bile potpuno usmerene ka podizanju svesti stanovništva o značaju kulture. Za tu svrhu se formirala posebna struktura kulturnih pregalaca koji su, kroz različite metode edukacije i animacije, okupljali građane svih socijalnih slojeva i životnih doba, podstičući ih da iskazuju svoje afinitete i skrivene talente kroz različite vrste amaterizma

11 Cvetičanin P., Kulturne potrebe, navike i ukus građana Srbije i Makedonije, Niš 2007, str. 101.

12 http://www.dictionaryofarthistorians.org/malrauxa.htm 
i konzumiranja kulturnih sadržaja. Međutim, politička situacija u tadašnjoj Jugoslaviji nije bila potpuno naklonjena slobodnom razvoju kulture, jer dogmatska ideja o bratstvu i jedinstvu, koliko god da je imala humani predznak, nije uzimala u obzir da „nacionalna kultura, kao ni nacija nije jednoobrazna, pa se pravo na identitet priznaje svim grupama koje čine naciju“"13. Ovo je dovelo i do birokratizacije u kulturnim centrima i posledično do zamiranja pravih oblika kulturne animacije. Razlozi za takvo stanje su mnogobrojni, ali posledice se osećaju i danas, tako da je neophodno pokrenuti određene aktivnosti, kako na nivou obrazovnog sistema tako i u okviru kulturnih institucija, na oživljavanju ideje o kulturnoj animaciji i opštoj afirmaciji prave kulture i umetnosti.

\section{Ciljevi istraživanja}

Osnovni cilj ovog istraživanja je bio usmeren ka utvrđivanju stepena poznavanja i primene kulturne animacije, na bazi čega bi mogao da se izradi predlog odgovarajućih akcija za afirmaciju animacije, kao jedne od najznačajnijih aktivnosti koju bi trebalo da sprovode i podstiču, kako institucije kulture tako i nadležna lokalna i državna uprava. Iako je animacija po svojoj prirodi dobrovoljna aktivnost otvorena za sve pojedince, pri čemu se ne zahteva posebno obrazovanje da bi se animacija razumela i da bi se u njoj učestvovalo, ipak takvu društveno osetljivu delatnost bi trebalo da vrše profesionalni animatori sa adekvatnim obrazovanjem.

Praktični cilj istraživanja se prvenstveno odnosi na utvrđivanje stvarnog nivoa konzumiranja kulturnih sadržaja i strukture aktivnosti, koje kulturne institucije sprovode radi povećanja posećenosti i povećanja zainteresovanosti kod šireg sloja stanovništva, koje tradicionalno ne pokazuje dovoljan interes za pravu kulturu. Indikatori koji bi se dobili iz ovog istraživanja bi trebalo da posluže za definisanje daljih kulturno-antropoloških istraživanja i utvrđivanje adekvatnih mera za zaustavljanje pada interesovanja za kulturu. Pored ove praktične upotrebljivosti istraživanja, rezultati bi trebalo da posluže i za usmeravanje pažnje određenih društvenih činilaca i institucija na aktuelne probleme kulturne i umetničke produkcije.

Sadržaj i način sprovođenja aktivnosti kulturne animacije su teorijski kontekst ove magistarske teze, a podaci dobijeni kroz istraživanje je trebalo da pokažu stepen korelacije između kvaliteta i kvantiteta animacije i obima konzumiranja konkretnih programa ponuđenih kroz animaciju. Jedan od ciljeva istraživanja je bio i stvaranje odgovarajuće baze podataka, koja bi mogla da

13 Dretar T., Animacija u kulturi, Kultura br. 45-46, Beograd 1979, str. 180. 


\section{MILOŠ ĆIRIĆ}

bude upotrebljena za definisanje naučno zasnovane platforme za razvoj i afirmaciju animativnih aktivnosti kao redovnog sadržaja rada kulturnih institucija.

\section{Hipoteze i teorijsko obrazloženje hipoteza}

Hipoteza 1.: Kulturna animacija kao kulturno-antropološki kontekst nije u dovoljnoj meri poznat rukovodećem kadru i organizatorima kulturnih programa u okviru najvažnijih kulturnih institucija Beograda.

Obrazloženje: Prema raspoloživim informacijama i dostupnim javnim dokumentima kulturna animacija nije značajnije zastupljena u planovima i programima kulturnih institucija niti nadležne lokalne i državne uprave. Razlog za neprimenjivanje takvih aktivnosti mogu biti višestruki, ali polazna pretpostavka je da nadležni planeri ne prepoznaju važnost kulturne animacije zbog nedovoljnog poznavanja njenog kako teorijskog tako i praktičnog značenja.

Hipoteza 2. Stepen afirmacije i nivo konzumiranja pojedinih kulturnih programa je u direktnoj korelaciji sa vrstom, obimom i kvalitetom promotivnih $\mathrm{i}$ animativnih aktivnosti.

Obrazloženje: Iskustva razvijenih zemalja sa dužom tradicijom u afirmaciji kulture i njenom približavanju direktnim konzumentima iz svih društvenih slojeva, kao i značajni rezultati u afirmaciji i podsticanju obrazovanja odraslih kroz različite programe kulturne animacije, govore u prilog navedenoj hipotezi.

\section{Kulturne institucije Beograda}

\section{Pojam i poreklo kulturnih institucija}

Institucije kulture čuvaju, organizuju, razvijaju kulturno stvaralaštvo i kulturno nasleđe. Svaka ozbiljna nacionalna zajednica osniva i održava svoje institucije kulture, među kojima su najbitnije: izdavačka preduzeća, biblioteke, muzeji, arhivi, likovne galerije, pozorišta, koncertne i muzičko-scenske dvorane.

U kulturne institucije se ubrajaju i razni instituti, zavodi i ustanove koji se bave proučavanjem, razvojem i popularisanjem nacionalne kulture i nasleđa. U Beogradu radi niz takvih institucija od nacionalnog značaja, kao što su Zavod za zaštitu spomenika kulture, Zavod za proučavanje kulturnog razvitka, Zavod za zaštitu prirode, Nacionalni javni radio i televizijski servis i niz kulturnih centra i domova kulture.

Kako se pojam „institucija“ često koristi u raznim kolokvijalnim značenjima, radi jednoznačnosti iskoristićemo sledeću definiciju preuzetu iz rečnika socijalnog rada. 
"Institucija je socijalna ustanova koja predstavlja sistem međusobno povezanih normi, čija je glavna funkcija zadovoljavanje bitnih ljudskih potreba na društveno regulisan način. Prema sadržini, institucije mogu biti: pravne, socijalne, ekonomske, političke, kulturne, religijske, naučne, obrazovne. Institucije su temelj kulture, civilizacije i zaloga njihove stabilnosti i kontinuiteta. ${ }^{14 "}$

Pored toga važno je istaći da je bitna stavka u funkcionisanju svake kulturne institucije njena organizacija i unutrašnja podela rada u zavisnosti od tipa i vrste institucije. Funkcionisanje jednog muzeja se u velikoj meri razlikuje od funkcionisanja jednog pozorišta, pa čak i dve institucije iz iste sfere delatnosti se mogu izuzetno razlikovati, na primer, Narodno pozorište se potpuno razlikuje od pozorišta Slavija. Razlike se vide počev i od osnovnih parametra, broj zaposlenih, broj sektora, veličina prostora sa kojim raspolaže, budžeta... Ali ono što ih povezuje i šta je suštinski najbitnije za rad svake institucije je njihova izuzetna društvena misija.

U Beogradu postoji više stotina kulturnih institucija, počev od lokalnog opštinskog značaja preko gradskog nivoa pa sve do elitnih institucija nacionalnog značaja. U taj broj ulazi i nekoliko desetina amaterskih društava koja, nezavisno od nivoa, predstavljaju veoma značajnu kariku u demokratizaciji kulture i približavanju kulture svim socijalnim slojevima.

Kultura kao par excellence socioantropološki fenomen se od samog nastanka ljudske civilizacije nalazila u središtu svih društvenih događanja, tako da su se paralelno sa razvojem društva i institucionalizacijom državnih struktura stvarale i raznovrsne kulturne institucije. Profilisanje kulturnih institucija kroz istoriju civilizacije je umnogome zavisilo od vrste društvenih odnosa, tako da se beleže uzleti i padovi u razvoju kako same kulture tako i kulturnih institucija. Industrijska revolucija je, pored opšteg društvenog napretka, donela i snažan zamah u razvoju kulture i njenog približavanja širim slojevima društva. Uočavajući značaj kulture u ukupnom društvenom razvoju, kao i njenu potencijalno subverzivnu snagu, političke strukture su shvatile da kontrolu nad kulturom mogu da ostvare kroz formiranje nacionalnih kulturnih institucija, koje su svojim delanjem uglavnom promovisale vladajuću doktrinu. O ovom fenomenu sociolog Slobodan Mrđa kaže: "Odnos društva i kulture na najneposredniji način obezbeđuje vezu između individualnog i kreativnog sa društvenim i javnim. Kultura, jedna od osnovnih dimenzija svakog društva, naročito je značajna za razumevanje procesa stvaranja, profilisanja i kristalizacije sistema vrednosti. Paralelno sa

14 Vidanović I., Rečnik socijalnog rada, Beograd 2006, str. 189. 


\section{MILOŠ ĆIRIĆ}

ovim procesom idu i nastojanja različitih političkih i ideoloških snaga da stave pod kontrolu pojedine segmente kulturnog života i stvaralaštva, pa je institucijama kulture vrlo teško da očuvaju neophodan stepen autonomije kao osnovnu pretpostavku slobode stvaralaštva. "'15 Ali potpuno je jasno kako ističe Koković da „stvaralačka klima zahteva otvorenost i dopuštanje suprotnosti. Kreativni proces traži mišljenja koja se suprotstavljaju; pojedinac svoje zamisli može proceniti tek u dijalogu i suprotstavljanju. Grupa, kolektiv ili društvo moraju biti otvoreni za različita mišljenja i za dopuštanje raznovrsnijih rešenja. Gušenje suprotnih mišljenja i drugačijih pogleda znači ometanje stvaralaštva, slabljenje klime za stvaralaštvo i povećanje nesigurnosti. Kreativnost se hrani problemima koji su otvoreni, koji su „nerešivi“,

kojima se čude i koji su, za mnoge, zagonetka i tajna"“16.

Upravo je sloboda stvaralaštva najviše ugrožena institucionalizacijom kulture odnosno načinom finansiranja projekata, pri čemu je od izuzetne važnosti ,da li odluku o finansiranju donose politički ili stručni organi. Veoma često se budžetski fondovi raspodeljuju u formi generalnih dotacija, bez preciznog definisanja šta se očekuje od institucija kulture u pogledu kvantiteta i posebno kvaliteta kulturnih aktivnosti. To gotovo uvek dovodi do stvaranja kulture zavisnosti, u kojoj caruju inertnost, rutina, nedostatak inovativnosti i političko podaništvo. Uvođenje elemenata takmičenja u bilo kojoj formi uvek deluje kao snažan podsticaj, pri čemu se različito operacionalizuje u različitim sektorima" ${ }^{\text {"17 }}$. Cvetičanin dalje obrazlaže aspekte procesa komercijalizacije kulture, u kojima na određeni način učestvuje i država, propisujući načine raspodele budžetskih sredstva, ali to neretko vodi gubitku kontrole nad kulturnom produkcijom, čime se dovodi u pitanje ukupan opstanak, ne samo kulture, već i niza privrednih delatnosti vezanih za nju.

\section{Beogradska potkulturna scena}

Potkultura ili supkultura postoji isto koliko i kultura, odnosno oba fenomena su nastala u praskozorje ljudske civilizacije, ali kao društvena pojava je počela da se sistematski istražuje tek posle prvog svetskog rata na čuvenoj čikaškoj školi sociologije. Jedno od kapitalnih dela u vezi supkulture je Human Migration and the Marginal Man, ${ }^{18}$ profesora Roberta E. Parka

15 Mrđa S., Kulturni habitus omladine, Zbirka eseja Mladi zagubljeni u tranziciji, priredio Mihajlović S., Beograd 2004, str. 158.

16 Koković D., op. cit., str. 309.

17 Cvetičanin P., Prilozi za definisanje strategije kulturnog razvoja grada Niša od 2004. do 2010. godine, Niš 2007, str. 20.

18 Ljudske migracije i marginalni čovek - marginalni čovek u ovom kontekstu znači mali, običan čovek. 


\section{MILOŠ ĆIRIĆ}

(Robert E. Park), koji je prvi uočio fenomen urbane otuđenosti kod doseljenika. Ali da bi se potpuno razumeo pojam potkulture, poći ćemo od jedne definicije kulture koju su dali Krober i Klakhon (Kroeber A.L. i Kluckhohn C. ${ }^{19}$ ), sublimirajući 160 definicija kulture iz različitih društvenih scena:

Kultura je sastavljena od matrice implicitnih i eksplicitnih simbola, koji čine karakteristična obeležja neke grupe ljudi, uključujući njihove artefakte i otelovljenja; srž kulture je sačinjena od tradicionalnih ideja (nastajalih i selekcionisanih kroz istoriju) kroz koje su eksplicitno izražene vrednosti; kulturni sistem može na neki način da se tretira kao produkt akcija, a takođe i kao preduslov za buduće akcije.

U nekim drugim definicijama se težište okreće na etnos, pa se može reći da se „najčešće pod kulturom podrazumeva skup tradicionalnih verovanja i stavova koji karakterišu i čine jedan narod, $\mathrm{tj}$. jedno organizovano društvo. Kultura, takođe, obuhvata način života, mišljenja i ponašanja koji se prenose s generacije na generaciju“20. Na bazi toga se može reći da je potkultura, posmatrano iz ugla sociokulturne antropologije, jedan od vidova kulture, ali ona ipak predstavlja svojevrsnu opoziciju dominantnoj kulturi i uglavnom se razlikuje od kulture kojoj pripada. Kako kaže Ken Gelder ${ }^{21}$ u predgovoru svoje knjige, potkultura se može shvatiti na šest načina:

vrlo često propagira negativan odnos prema radu i radnim obavezama, lenčarenje, parazitski način života, hedonizam, kriminal;

negativan ili ambivalentan odnos prema priznatim društvenim klasama;

vezanost za određenu teritoriju, ulicu, komšiluk ili klub znatno više nego za sopstveni dom;

napuštanje kuće i život u neporodičnom okruženju u formi ,pripadanja“;

preterano isticanje međusobne povezanosti pripadnika (za razliku od umerenosti i uzdržanosti);

19 Kroeber A. L. i Kluckhohn C., Culture: A critical review of concepts and definitions, Harvard University Peabody Museum of American Archeology and Ethnology Papers 47. 1952, citirano u Routledge i Kegan P., The sociology of youth culture and youth subcultures: sex and drugs and Rock ' $n$ ' Roll?, London 2008, str. 6.

20 Koković D., op. cit., str. 27.

21 Gelder K., Subcultures: Cultural Histories and Social Practice, Routledge, NY 2007. 
MILOŠ ĆIRIĆ

indignacija prema običnom svakodnevnom životu, a posebno prema izjednačavanju sa masom.

Potkultura obuhvata ogroman broj različitih grupa od jeretika do ekstremnih feministkinja, od „sponzoruša“ do teških narkozavisnika, od džezera do turbo-folk fanova, od kicoša do pankera, od hipija do boema, od navijačkih grupa do šovinista. Moglo bi se nabrojati još desetine različitih obeležja, ali veoma često im je zajednički imenitelj asocijalno i kriminogeno ponašanje.

Ni Beograd nije imun na pojavu potkulture, koja se u današnjem obliku i raznolikosti razvija tek u drugoj polovini osamdesetih godina prošlog veka, kada autoritarna vlast svoju pažnju usmerava na očuvanje svoje pozicije i kada počinje u tu svrhu da koristi različite potkulturalne grupe. Ne ulazeći u složenu sociološku prirodu i poreklo potkulture, dolazi se veoma lako do zaključka da je veliki deo pripadnika potkulturnih pokreta proizvod nezainteresovanosti države za promociju pravih vrednosti među

kojima kultura zauzima veoma visoko mesto.

\section{Specifičnosti omladinskih potkultura}

Potkultura inherentno sadrži određenu dozu bunta, različitosti i subverzivnosti što se u potpunosti podudara sa adolescentnim načinom posmatranja okruženja. Ovo ni u kom slučaju ne znači da sve aspekte potkulture mladih treba tretirati kao društveno „neprihvatljivo“ ponašanje već treba u tome tražiti naznake potreba i htenja mlade generacije. „Što se tiče stvaranja identiteta potkulture, ključni stav je da se potkulture formiraju i postaju prepoznatljive preko niza dinamičkih opozicija/distinkcija koje se formiraju kako u odnosu prema svom spoljnom okruženju tako i unutar nje same. Tako možemo razlikovati spoljašnje i unutrašnje komponente identiteta potkulture."

Upravo se u tome iskazuje specifičnost potkulture mladih nastala na potrebi samopotvrđivanja u okviru grupe, koja je najčešće deo lokalnog okruženja ili škole. Na formiranje specifične potkulture mladih najveći uticaj upravo ima slobodno vreme, koje mladi uglavnom koriste za razne vrste druženja. Ovaj fenomen je odavno poznat, pa su se sociolozi i psiholozi u godinama posle drugog svetskog rata zdušno trudili da osmisle i ponude modele takozvanih vanškolskih aktivnosti. Ovo je posebno bilo izraženo u društvima socijalističkog bloka, gde se do apsurda nastojao „osmisliti“ svaki slobodan trenutak mladih ljudi. U tom kontekstu treba posmatrati i fenomen slobodnog vremena $u$ današnjim okvirima, kada se u opštoj demokratizaciji lična sloboda svih, uključujući i najmlađu populaciju, ističe kao najviši civilizacijski domet. „Način provođenja slobodnog vremena je jedna od određujućih karakteristika stila života mladih, a kada 


\section{MILOŠ ĆIRIĆ}

su srednjoškolci u pitanju, upravo u tim sekvencama dana mladi dobijaju slobodan prostor za lični (i grupni) izbor. Tek kada pritisak odraslih popusti, kada se zaustave svakodnevne rutine, mladi imaju priliku da pokušaju da otkriju ko su oni zaista, šta i koga vole ili ne vole, šta žele da postanu. Za mlade, gotovo da nema važnijeg vremena od slobodnog vremena!“‘

Uočavajući ovaj problem, Zavod za proučavanje kulturnog razvitka sproveo je krajem 2010. godine istraživanje "Kulturni život i potrebe studenata univerziteta u Srbiji"22. Istraživanje je obuhvatilo studente između 19 i 27 godina na deset univerziteta. Prema rezultatima istraživanja može se konstatovati da studenti imaju relativno malo slobodnog vremena, tako da najveći broj studenata jedva da imaju tri sata dnevno slobodnog vremena za odmor ili zabavu. Ali je vrlo indikativno da bavljenje umetnošću i odlazak u neku od institucija kulture nisu omiljeni načini provođenja slobodnog vremena kod studenata. Porazna je činjenica da samo $7 \%$ studenata od kojih $60 \%$ iz Beograda slobodno vreme provodi u nekoj od institucija kulture, time je stvoren prazan prostor koji u velikoj meri zauzima neki od vidova potkulture. Ipak, slobodno vreme studenti najvećim delom provode u sportskim aktivnostima, za kompjuterom, na internetu, ili spavajući i dosađujući se, dok se studentkinje radije druže sa prijateljima, izlaze u grad, kafiće, klubove i nešto ređe odlaze u neku od institucija kulture.

Kako razgraničenje između prave kulture i potkulture nije oštra linija već je granica šira ili uža „ničija“ zemlja, potpuno je jasno da delovi potkultura polako prerastaju u kulturu što se može videti u nizu pravaca pop-arta, koji su u vremenu svog nastanka bili predmet sveopšte kritike. Jedan od upečatljivih primera je Endi Vorhol (Andy Warholl23), osporavana ikona pop-arta, čija se dela danas nalaze u najprestižnijim svetskim muzejima i galerijama. Ali ipak potkulturu, čak i njene benigne oblike, treba kanalisati u skladu sa postojećim kulturnim obrascima i nastojati da se očuva kulturna raznolikost, koja je dramatično napadnuta agresivnom globalizacijom.

\section{Noćni život}

Na marginama tih pravih vrednosti, Beograd je postao mesto sa veoma razvijenim noćnim životom i kontraverznim mestima zabave, kako što su splavovi na Savi i Dunavu, ali i čuvena „silikonska dolina" kako se u žargonu naziva jedna, nekada vrlo mirna beogradska ulica. Veliki doprinos razvoju hedonizma te

22 Mrđa S., Život i potrebe studenata u Srbiji, http://www.zaprokul.org.rs/Media/Document/a4071be6224d4414a7ffc0d57e7153dd.pdf

23 Andy Warholl 


\section{MILOŠ ĆIRIĆ}

vrste dala je i licemerna ocena da je Beograd najbolje mesto za provod na svetu, jer kako se navodi „u Beogradu noću može da se uživa na milion načina i da se pronađe sve za svakoga - od jazz klubova, preko mesta gde se celu noć igra tango i salsa do irskih pubova i klasičnih diskaća sa prelepim devojkama“"24. U toj oceni se ne navodi da se na nekim od tih mesta skoro javno prodaju narkotici svih vrsta, da se otvoreno ili prikriveno nudi prostitucija, vrlo često povezana sa trgovinom ljudima i ucenama različitih vrsta. Jedan od razloga za ovu pojavu je velika disproporcija između želja i mogućnosti mlađe generacije, zavedene sjajem ponude prestižne, a mahom nedostupne robe, za čije sticanje se često ne biraju sredstva, po makijavelističkom principu da cilj opravdava sredstva, čime se taj pogubni circulus vitiosus $^{25}$ zatvara.

Iznošenje ovih činjenica o beogradskom noćnom životu u negativnoj konotaciji nije implicitna sugestija za njegovo ukidanje, već je pokušaj skretanja pažnje na nedovoljno angažovanje društva u pravcu afirmisanja pravnih vrednosti i usmeravanja mlađe populacije na druge društveno prihvatljivije načine samopotvrđivanja. Takođe je bitno istaći da nedostatak prave sociokulturne animacije ostavlja veoma veliki prostor za masovno regrutovanje adolescenata u razne kriminogene organizacije, kao što su navijačke grupe, nacionalističke organizacije, pa čak i u ulične bande, kojih je u poslednjim godinama sve više.

\section{Boemski Beograd}

Tačnost latinske izreke Exceptio afirmat regulam ${ }^{26}$ potvrđuje i činjenica da supkultura nema uvek negativan predznak, jer nekadašnji romantičan boemski Beograd, kao specifičan oblik urbane supkulture, bio je izvorište veoma bogatog i kreativnog umetničkog stvaralaštva sa početka prošlog veka. Boemski Beograd se vezuje za kafane locirane u Skadarliji, gde je bilo stecište najpoznatijih imena kulturnog Beograda, koji su se, posle rušenja poznate kafane „Dardaneli“, preselili u kafane Skadarlije. Tu su mnoge viđene domaće i strane glave „svoje najlepše dane - provodili noću“. Tu su nastale i čuvene starogradske pesme, koje su i danas popularne i koje predstavljaju beogradski ,ever green“. Skadarliju su najčešće poredili sa pariskim Monmartrom, kako po izgledu, tako i po veseloj, uzavreloj umetničkoj atmosferi. U Skadarliji su nekada stanovali mnogi poznati književnici, glumci, slikari i novinari, među njima je svakako najpoznatiji čuveni srpski pesnik i slikar Đura Jakšić. Njegova kuća

24 Najpoznatiji turistički vodič na svetu Lonely Planet.

25 Začarani krug

26 Izuzetak potvrđuje pravilo. 
je danas pretvorena u sastajalište pesnika „Skadarlijskih večeri“. U današnjoj Skadarliji, koja je izuzetna turistička atrakcija Beograda, nalaze se poznati restorani „Tri šešira“, „Ima dana“, „Dva jelena“, „Skadarlija“, „Zlatni bokal“, „Dva bela goluba“ $\mathrm{i}$ „Putujući glumac“, zatim galerije, prodavnice antikviteta i suvenira. ${ }^{27} \mathrm{U}$ današnje vreme, kada je sve zahvatila opšta komercijalizacija, polako nestaje i taj Beograd potisnut turbo-folkom, koji svojim decibelima onemogućava bilo kakvu verbalnu komunikaciju među gostima tih kafana, a koja je bila osnova druženja nekadašnjeg boemskog Beograda i koja je ostavila desetine duhovitih dosetki i anegdota iz tih vremena. Za „umiranje“ čuvene beogradske boemštine ipak nije kriv samo turbo-folk, a možda je on i najmanje zaslužan za to. Razloge treba tražiti u globalizaciji, neprihvatljivoj brzini življenja, otuđenju, brzoj hrani i kafi „za poneti“ i svim drugim razlozima koji nas sprečavaju da se družimo i „traćimo“ vreme u naizgled beskorisnim razgovorima. Gubitak svake vrste direktne komunikacije, sužavanje vokabulara na neshvatljiv minimum, SMS, Fejsbuk, slušalice u ušima MP3 plejera, virtuelne društvene mreže ubrzano ruše većinu važećih sociopsiholoških postulata društvenih odnosa, a time i fenomene kao što je boemski život ili aktivno druženje bilo koje vrste.

\section{Promocija kulture u Beogradu}

Po rečima Lorana Heđija, ${ }^{28}$ umetničkog direktora 48. Oktobarskog salona, Beograd je „kulturna prestonica Balkana“. Uz to, posebno naglašavajući da „Beograd ima energiju koja dugo živi”, Heđi stavlja akcenat na više milenijumsku kulturnu baštinu Beograda, koja tom svojom energijom i raznovrsnošću napaja i današnje kulturne stvaraoce grada.

U Beogradu se velika pažnja posvećuje promociji kulture, u koju su uključene brojne gradske institucije i organizacije pod koordinacijom Gradskog sekretarijata za kulturu. Aktivnosti na promociji kulture su mnogobrojne i najveći deo njih su povezane i sa određenim programskim sadržajima kao što su Oktobarski salon, Bemus, Belef, Noć muzeja i još tridesetak manifestacija uglavnom međunarodnog karaktera, koje upotpunjuju sliku o Beogradu kao velikom centru kulture i umetnosti. Pored toga, pod pokroviteljstvom grada, dodeljuje se i nekoliko prestižnih nagrada za kulturno stvaralaštvo među kojima izdvajamo dve najznačajnije:

Zlatni beočug, koji od 1970. godine dodeljuje Kulturnoprosvetna zajednica Beograda. To je priznanje za zaokružene

27 Priređeno prema tekstu sa sajta Turističke organizacije Beograda.

28 Lorand Hegyi, direktor Muzeja savremene umetnosti iz Sent Etjena. 
MILOŠ ĆIRIĆ

duhovne vrednosti i dostignuća, što kontinuirano povezuju sve one koji omogućuju uspešniji duhovni život Beograda ${ }^{29}$;

Nagrada grada Beograda je nasledila Oktobarsku nagradu grada Beograda koja se decenijama dodeljivala 20. oktobra, na godišnjicu oslobođenja Beograda od nemačke okupacije u Drugom svetskom ratu, ali promenom datuma glavnog gradskog praznika, koji se sada zove „Dani Beograda“30 i nagrada je dobila drugo ime, ali je i dalje jedna od najprestižnijih nagrada za kulturno, umetničko ili naučno stvaralaštvo.

Pored ovih nagrada postoji i više desetina drugih nagrada za kulturno, umetničko i naučno stvaralaštvo, ali se one dodeljuju od strane raznih fondacija, kulturnih institucija i organizacija ili privatnih preduzeća sa delatnostima vezanim za kulturu. Neke od ovih nagrada su veoma značajne i prestižne, kao što je na primer Ninova nagrada za roman ili Vukova nagrada za doprinos razvoju kulture u Srbiji, Kulturno-prosvetne zajednice Srbije. Iako sve ove nagrade imaju prevashodni cilj podsticanje kulturnog i umetničkog stvaralaštva i njihovog promovisanja, stiče se utisak da medijsko praćenje njihovih dodela i medijska promocija laureata nije u skladu sa značajem nagrada. Znatno veća pažnja se posvećuje nagradama za stvaralaštvo od marginalnog značaja za ukupnu nacionalnu kulturu, ali koje je nažalost znatno popularnije od prave kulture i umetnosti. Stiče se utisak da Ministarstvo kulture Srbije pokušava da reaguje na ovu pojavu, ali budžetska ograničenja im u izvesnom smislu vezuju ruke. Da li je rešenje u podsticanju mecenstva ili u većem poreskom opterećenju kiča i šunda ili u nekom trećem izvoru dodatnih budžetskih prihoda, teško je reći, ali je potpuno jasno da je potrebno nešto učiniti u vezi toga. Ali postoje i svetli primeri afirmacije kulture življenja i konzumiranja onih kulturnih sadržaja koji spadaju u domen prave kulture. Jedna od takvih inicijativa je i projekat „Beogradizacija Beograda“ koji je pravi primer pravilno shvaćenog značenja sintagme ,sociokulturna animacija“ u kojoj je težište na oživljavanju i očuvanju autentičnih beogradskih vrednosti i kulture. Izmeštajući kulturne sadržaje u prostore koji nisu naviknuti na to, pokazuje se da kultura nije samo odlazak u pozorište, koncert umetničke muzike, u muzej ili na izložbu, već je to permanentna akcija u afirmaciji pravih kulturnih vrednosti i promena načina života.

Afirmacija kulture je prevashodno zadatak svih institucija kulture, ali ne treba zaboraviti da se sistem vrednosti i estetski kriterijumi grade od najranijeg detinjstva, te iz tog razloga obrazovni sistem mora sa više entuzijazma i napora da pristupi tom

29 Sa sajta časopisa Drama - http://www.drama.org.rs/

30 “Dani Beograda” se održavaju svake godine u periodu od 16. do 19. aprila. 
problemu. Veoma često se objavljuju istraživanja o ogromnom procentu dece i omladine koja ne čitaju ni obaveznu lektiru, a da ne govorimo o navici da se permanentno čita „lepa književnost“"31. Posledice su pogubne, deca nedovoljno vladaju sopstvenim jezikom uz veoma ograničen vokabular prepun žargonskih reči i izraza, što ih u velikoj meri sputava i da potpuno razumeju iole ozbiljniji tekst. Izvestan broj dece ostaju trajno funkcionalno nepismena što ih kasnije onemogućava da nastave školovanje ili da se zaposle. Prema istraživanju, ${ }^{32}$ koje je sproveo Institut za pedagoška istraživanja, stanje nije zadovoljavajuće i potrebno je raditi na poboljšanju pismenosti kod dece školskog uzrasta jer ,jezička kultura je nezaobilazni deo opšte kulture, pa bi njenim unapređenjem bio podignut opšti kulturni nivo kako pojedinca, tako i cele zajednice ${ }^{\text {“633 }}$. Pored toga, za proaktivan pristup rešavanju ovih problema potrebno je posebno angažovanje svih relevantnih institucija na afirmaciji kulture i umetnosti mladih i razvoju građanskog društva. Pri čemu je potrebno posebno istaći značaj uvažavanja savremenih demokratskih principa kao što su tolerancija, interkulturalnost, poštovanje prava na polnu, versku, socijalnu, seksualnu, nacionalnu ili bilo koju drugu različitost.

\section{Kulturni potencijali Beograda}

Kulturni potencijali Beograda nisu samo u prethodno kulturnim institucijama, koje čine najznačajniji deo kulturne scene Srbije, već se najvećim delom nalaze u ogromnom kreativnom potencijalu niza značajnih beogradskih umetnika i stvaralaca. Za plodotvorno korišćenje i usmeravanje ovog ogromnog potencijala zaslužne su prvenstveno brojne kulturne institucije, ali svakako i gradska uprava koja kulturi pridaje izuzetan značaj.

Ali nije sve tako idilično i podsticajno kao što bi se moglo pomisliti, jer hroničan nedostatak novca potiskuje neke vidove kulturnog stvaralaštva na margine kulturne scene grada. Iz tog razloga bi gradski kulturni planeri trebalo da povedu više brige o ,malim“ umetničkim projektima i da ih podrže kako organizaciono tako i finansijski. Pored toga bilo bi dobro da udruže snage sa drugim gradskim i republičkim strukturama kako bi se stvorili preduslovi da kultura bude dostupnija širim slojevima stanovništva. Ta dostupnost se može postići boljom saobraćajnom infrastrukturom, ali i tako što će se objekti kulturne infrastrukture obnavljati i graditi i u prigradskim i ruralnim područjima grada.

31 Lepa književnost potiče od francuskog izraza Belles lettres, koji je u srpskom jeziku odomaćen kao beletristika.

32 Stevanović J., Maksić S. i Tenjović L., Istraživanje o pismenom izražavanju učenika osnovne škole, Zbornik Instituta za pedagoška istraživanja, Beograd, Godina 41, Broj 1, Jun 2009, str. 147-164.

33 Ibid., str. 162. 


\section{MILOŠ ĆIRIĆ}

Potpuno je jasno da je žiteljima Obrenovca, Sopota ili nekog ruralnog dela Beograda odlazak na neku večernju predstavu, u neku od gradskih dvorana, prava avantura, ukoliko koriste javni prigradski prevoz. Kako taj problem nije moguće brzo prevazići, mada je Gradska uprava već uložila značajna sredstva u poboljšanje javnog prevoza, potrebno je sistematski planirati gostovanja u tim sredinama onih programa koje je moguće izvesti u postojećim objektima kulture. To ne moraju prevashodno da budu izvođački i scenski programi, već to mogu biti i razne trbine, književne večeri, izložbe, a takođe i umetničke radionice u školama ili domovima kulture. $U$ ove aktivnosti bi morali biti mnogo više uključene nezavisne kulturne organizacije, koje su znatno otvorenije za avangardne i nekonvencionalne pristupe afirmaciji prave kulture i umetnosti.

Očuvanje i razvoj kulturnih potencijala Beograda je od esencijalnog značaja za turističku privredu grada, a i cele Srbije, pri čemu je to čitav lanac privrednih aktivnosti na čijem vrhu je turizam. Ova činjenica se mora uvažavati kod izrade svih planova razvoja grada, prvenstveno uključivanjem stručnjaka za kulturnu animaciju u timove za izradu planova, koji bi svojim iskustvom pomogli da se kulturni potencijali grada maksimalno istaknu i iskoriste. Najbolja provera kvaliteta rada kulturnih pregalaca Beograda će biti izveštaj o proglašenju Evropske prestonice kulture 2020, koje će biti objavljen posle 2015-te, ali do tada Beograd mora da učini niz koraka kako u političkom i promotivnom smislu tako i u pravcu poboljšanja uslova za svekoliki kulturni rad i pregalaštvo u Beogradu. „Evropska prestonica kulture nije samo prilika da muzeji, pozorišta, bioskopi, kongresne $\mathrm{i}$ koncertne dvorane, biblioteke $\mathrm{i}$ istorijska mesta dobiju novi sjaj i da se grad ulepša. To je i šansa da se uspostave novi kulturni standardi, da se urede odnosi između stvaralaca, publike,

$$
\text { tržišta i države. “34 }
$$

Član 5. odluke Evropskog parlamenta o izboru prestonice kulture Evrope ${ }^{35}$, kaže između ostalog:

„Svaki grad će organizovati program kulturnih događaja isticanjem sopstvene gradske kulture i kulturne baštine, kao i svog mesta u zajedničkom kulturnom nasleđu, kao i uključivanjem ljudi koji se bave kulturnim aktivnostima iz drugih evropskih zemalja sa ciljem da se uspostavi trajna saradnja. Pored navedenog, listu za planiranje i evaluaciju kriterijuma navedenu $u$

34 Mučibabić D. i Vukotić D., Kako do titule evropske prestonice kulture, Politika, Beograd 13. 06. 2010, str. 19.

35 Decision 1419/1999/ec of the European parliament and of the Council of 25 may 1999 establishing a Community action for the European Capital of Culture event for the years 2005 to 2019 . 
Aneksu II, svaki grad treba, u najvećoj mogućoj meri, da uzme u obzir kod planiranja svog programa. U principu ovaj program bi trebalo da traje godinu dana, ali izabrani gradovi, u izuzetnim slučajevima, mogu da se odluče za kraći vremenski period. Gradovi, po nahođenju, mogu da uključe svoju okolinu u svoje programe. Potrebno je da postoji veza između programa izabranih gradova iz iste godine."

Prema ovoj odluci za prestonicu kulture mogu biti izabrani i gradovi izvan EU, tako da će svi relevantni činioci na nivou grada i Republike uložiti maksimalan napor da se zahtevani standardi ispune i da se steknu uslovi za izbor Beograda za tu laskavu titulu. Za sada je na nivou grada, za ovu svrhu, oformljen Organizacioni odbor koji bi trebalo da predloži „plan puta“ za postizanje ovog značajnog cilja, na bazi koga će se oformiti radni timovi za sve glavne aktivnosti i utvrditi potrebni budžeti po godinama realizacije. Bitno je istaći da će projekat biti finansiran samo jednim delom iz gradskog budžeta, dok će veći deo sredstva biti obezbeđen iz republičkih izvora i inostranih donacija. To je i razumljivo kad se ima u vidu promotivna vrednost te laskave titule za celu naciju, a ne samo za konkretan grad. Iz tog razloga se očekuje da na ovom projektu budu angažovani najkreativniji stvaraoci i menadžeri u kulturi ne samo iz Beograda već iz cele Srbije, a po mogućstvu i neki istaknuti Evropski kulturni pregaoci.

Posebno je značajno istaći da će ova koordinirana akcija najviše pomoći nekomercijalnoj kulturi koja godinama vapi za finansijskim sredstvima kako bi pokrenula neke, sa umetničkog stanovišta, veoma vredne projekte. S druge strane, afirmacija Beograda kao kulturne destinacije će ostati kao trajna vrednost koja nije ograničena samo na godinu u kojoj bi Beograd bio prestonica kulture Evrope.

\section{Zaključak}

Ne pružanje pomoći i doprinosa istraživanju, nedostatak literature, težak ili nemoguć pristup javnim dokumentima i podacima, samo su najveći problemi na koje se nailazilo u istraživačkom procesu vezanim za ovaj rad. Što samo po sebi nameće zaključak da kulturni prostor Srbije ne samo da nije dovoljno istražen već da se na istraživanja bilo koje vrste i ne gleda baš pozitivno. Razlozi za ovakvo stanje su uglavnom implicitni, pa i teže dokazivi, ali kroz proces uopštavanja se vrlo brzo uočava izvorište većine razloga.

Prvo, značajan broj menadžera i organizatora kulture nema kulturni background već su se u kulturi našli kroz međupartijsku raspodelu. Ovo možda i ne bi bila najgora vest da takvi kadrovi 
MILOŠ ĆIRIĆ

imaju bar garanciju da će ostati neki značajniji period u vodama kulture već, svesni sveopšte kratkoročnosti, odmah gledaju gde će im biti sledeća pozicija.

Drugo, eminentni kulturni radnici i sposobni organizatori su uglavnom nezavisni, a samim tim i nepodobni za ključne funkcije, na kojima se gradi kulturna politika uključujući i budžetsku raspodelu. Većina takvih stvaralaca jedva uspeva uz ogromne napore da održe svoj rad ili realizuju svoje projekte, čime uglavnom iscrpljuju svoju energiju i volju da nešto šire učine. Pojedini vidovi stvaralaštva su skoro potpuno marginalizovani, tako da se većina umetnika „bavi“ umetnošću uz neki manje ili više trivijalan posao koji rade zbog pukog preživljavanja.

Treći, a verovatno i najznačajniji razlog, predstavlja nestanak institucijalnih oblika kulturoloških istraživanja i zamiranje naučno-istraživačkog rada. Bez fundamentalnih antropoloških istraživanja i podrške nekomercijalnim projektima svaka nacionalna kultura je osuđena na nestanak i asimilaciju od strane globalne supkulture. Potrebu očuvanja tradicije i kulturne raznolikosti je uočio i UNESCO u vezi čega je objavljeno više međunarodnih konvencija, od kojih je i Srbija veći broj usvojila. Međutim, samo usvajanje je politički čin koji međunarodna zajednica sa pravom očekuje, ali u većini slučajeva se tu i završava

proces.

Navedeni problemi su samo neki od vidljivih delova ledenog brega, i potpuno je jasno da se ni oni niti ostali problemi ne mogu rešiti preko noći. Međutim, mora se imati na umu da je osnovani metod za rešavanje problema bilo koje prirode, prvo utvrđivanje uzroka, a potom na bazi njih i definisanje adekvatnih mera. Isticanje ove činjenice nema pretenziju da ponudi neki univerzalni metod za rešavanje svih problema u kulturi Srbije. Ali uočena uzročno-posledična veza između pada interesovanja za pravu kulturu i okretanja šireg sloja stanovništva prema takozvanoj „Pink“ kulturi, sada dodatno „ojačanoj“ nizom rijalitija kao apsolutnim dnom tog dugotrajnog procesa, na neki način implicira i pravac rešavanja.

Evropska iskustva u rešavanju ovih problema, na koje nisu ni razvijene zemlje imune, govore da se sistem i hijerarhija kulturnih vrednosti formira još u ranom detinjstvu kroz uticaj okruženja, a posebno obrazovnih programa. Iz tog razloga su i pokrenuti brojni projekti deelitizacije prave kulture i njeno usaglašavanje sa percepcijom mlade generacije. Ovaj proces je direktno povezan sa efektivnom kulturnom animacijom, koja umnogome pomaže da se razbiju predrasude i tabui uglavnom stečeni kroz ogroman uticaj tabloidne štampe i komercijalnih televizija. U skladu sa tim potrebno je konkurisati za određena sredstva kod 


\section{MILOŠ ĆIRIĆ}

pristupnih fondova EU, koji će biti još pristupačniji sticanjem statusa kandidata koji će Srbija dobiti u narednom kratkoročnom periodu. Ove aktivnosti treba u što većoj meri sinhronizovati sa radom na kandidaturi Beograda za kulturnu prestonicu Evrope 2020, i takođe iskoristi povoljne okolnosti koje ta kandidatura donosi u smislu povezivanja Beograda sa drugim kulturno razvijenijim evropskim gradovima.

\section{LITERATURA:}

Cvetičanin P., Kulturne potrebe, navike i ukus građana Srbije i Makedonije, Odbor za građansku inicijativu Niš, Niš 2007.

Farik N., Eseji i intervjui, Povratak u šezdeset osmu - 40 godina od protesta, Fondacija „Heinrich Böll”, Regionalni ured Beograd, 2008, http://www.fondacija-boell.eu/

Gelder K., Subcultures: Cultural Histories and Social Practice-Routledge, NY 2007.

Kalanj R. i Sudović Z., Značenje i organizacijske pretpostavke kulturne animacije, Kulturna i edukativna akcija u radnoj sredini i lokalnoj zajednici - Prilozi Zavoda za kulturu Hrvatske, Zagreb 1979.

Koković D., Pukotine kulture, Prometej, Novi Sad 2005.

Stepanović I., Videnović M. i Plut D., Obrasci ponašanja mladih tokom slobodnog vremena - Izvorni naučni članak UDK: 316.356.2, Sociologija, Vol. XLIX (2007), $\mathrm{N}^{\circ} 3$.

Stojanović D., Od potkulture do scene i plemena: postbirmingemski pristupi u analizama odnosa omladine, muzike i stila - Pregledni naučni članak UDK: 316.723-053.6 - Sociologija, Vol. XLIX (2007), № 3.

Vidanović I., Rečnik socijalnog rada, Udruženje stručnih radnika socijalne zaštite Srbije i Asocijacija centara za socijalni rad Srbije, Beograd 2006.

Mihajlović S., Zbirka eseja Mladi zagubljeni u tranziciji, Centar za proučavanje alternativa, Beograd 2004. 


\title{
MILOŠ ĆIRIĆ
}

\author{
Miloš Ćirić \\ European Center for Peace and Development (ECPD UN) - \\ Management in Culture and Arts

\section{CULTURAL ANIMATION AND CULTURAL INSTITUTIONS}

\begin{abstract}
The cultural tradition of Belgrade, created over several millennia of rises and falls, is one of the major city resources. However, culture did not get its deserved place in the strategic plans of Serbia, nor of Belgrade. This fact must be changed as soon as possible through a series of synchronized and meaningful actions, including a revival of the idea of cultural animation, not only as a subject of research projects but as a real activity of all relevant public and cultural institutions. Initial activities should cover evaluation of the real state of culture in Belgrade, preparing a list of cultural institutions of all levels and orientations, and also through a wider survey of cultural needs and habits of the population of Belgrade. Such researches should be a basis for defining a list of appropriate actions to articulate and stream the interests of Belgrade population towards true culture, but also free of elitism. Bringing culture to the population through educational and inspirational programs for youth and organizing specific programs in rural and suburban areas should be the key element of the newly established animation programs. In addition to this, already wellestablished cultural institutions need to join or support the activities of cultural entertainment that would be coordinated at the level of city government.
\end{abstract}

Key words: Cultural tradition, cultural institutions, cultural animation, city government

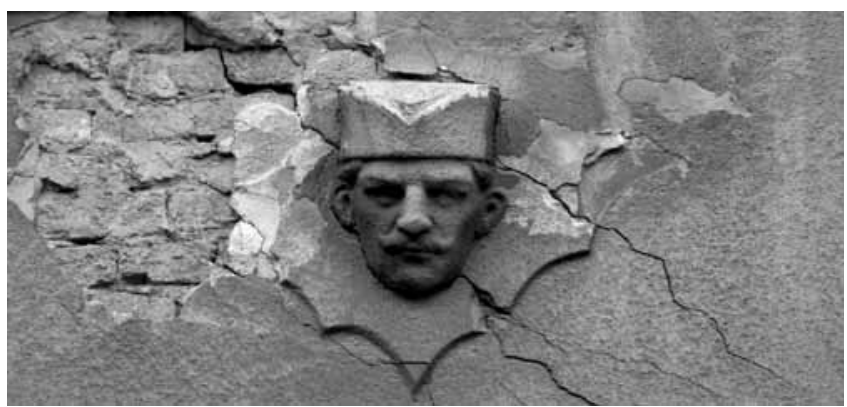

Siniša Stefanović, Na položaju, Beograd 2011. 